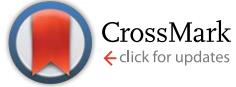

Cite this: RSC Adv., 2016, 6, 88373

Received 1st July 2016

Accepted 29th August 2016

DOI: 10.1039/c6ra16913a

www.rsc.org/advances

\section{Effectiveness and mechanisms of ammonium adsorption on biochars derived from biogas residues}

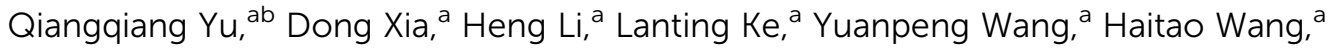 \\ Yanmei Zheng*a and Qingbiao Li*ac
}

\begin{abstract}
The solid by-product of anaerobic digestion derived biochar has been used as an adsorbent for the liquid by-product and is a viable and environmental friendly way to control waste. In this study, two biochars (BC-PM, BC-ST) from pig manure biogas residue (BR-PM) and straw biogas residue (BR-ST) were assessed for ammonium adsorption. The ammonium adsorption on both BC-PM and BC-ST followed the Elovich kinetic model and fit well with the Langmuir isotherm, whereas BC-PM was better than BC-ST at absorbing ammonium. In addition, the adsorption mechanism was elucidated by analysing the physicochemical properties of the biochars. The Brunauer-Emmett-Teller (BET) surface area, pore structure and micromorphology, which are mainly related to the carbon in the biochars, had no direct correlation with the ammonium adsorption capacity. However, the ash in the biochars played an important role in ammonium adsorption. The metal elements in biochar ash significantly decreased after adsorption, especially potassium, which nearly disappeared as a result of ion exchange with ammonium. However, the quartz and carbonate mineral in biochar ash also functioned as ammonium adsorption sites according to Fourier transform infrared spectroscopy (FT-IR) and X-ray diffraction (XRD) analysis. This study revealed the irreplaceable role of ash in biochars for ammonium adsorption, which will guide the preparation of biochars from different types of feedstocks for ammonium adsorption.
\end{abstract}

\section{Introduction}

Anaerobic digestion for waste management and renewable energy production contributes considerably to environmental protection and the attention on energy recovery has grown in recent years. ${ }^{\mathbf{1 , 2}}$ However, biogas digestate, the inevitable by-product is produced in large quantities and must be handled and utilized appropriately because of its potential risk of repeated pollution..$^{3-5}$ In particular, solid, biogas residue that contains high proportions of hemicellulose, lignin and ash etc., is also a good precursor of biochar which is a carbon-rich solid product generated from pyrolyzing biomass, including rice husk, sugarcane bagasse, manure and biogas residues with the exclusion of oxygen. ${ }^{6-9}$ Biochars have good stability and physicochemical properties and have been developed as absorbents to remove pollutants such as aromatic contaminants, heavy metals, dyestuff and ammonium. ${ }^{\mathbf{1 0 - 1 3}}$

${ }^{a}$ Department of Chemical and Biochemical Engineering, College of Chemistry and Chemical Engineering, Xiamen University, Xiamen 361005, P. R. China. E-mail: zym@xmu.edu.cn; kelqb@xmu.edu.cn

${ }^{b}$ Zhejiang Provincial Key Laboratory of Water Science and Technology, Department of Environment in Yangtze Delta Region Institute of Tsinghua University, Zhejiang, Jiaxing 314006, P. R. China

${ }^{c}$ College of Chemistry and Life Science, Quanzhou Normal University, Quanzhou 362000, P. R. China
Ammonium is one of the most abundant contaminants in the liquid by-product (biogas slurry) after anaerobic digestion and is also a common nutrient in wastewater from industrial, agricultural and household activities. It contributes to the eutrophication of rivers and lakes, ${ }^{\mathbf{1 4 , 1 5}}$ and even $0.2 \mathrm{mg} \mathrm{L}^{-1}$ can be toxic to aquatic life. ${ }^{\mathbf{1 6}}$ Adsorption is a feasible process for ammonium removal and has been well documented by many researchers. Meanwhile, numerous types of absorbents such as zeolite, fly ash and sepiolite, among others, have been developed, with a key production point being low-cost and highefficiency. ${ }^{17-20}$

As low-grade biomass, biogas residue derived biochars are inexpensive. More importantly, biochars possess particular advantageous properties. For example, some studies note the cost advantage of biochars derived from fermentation residue, ${ }^{\mathbf{2 1 - 2 3}}$ and revealed that these biochars had better adsorption properties than undigested feedstocks used directly. ${ }^{24}$ Although there is little information on the ammonium absorption properties of biochars derived from biogas residues, the studies of biochars produced from other biomass also provide a wealth of inspiration. Biochars prepared from plant biomass, ${ }^{25}$ corn cob,${ }^{13}$ giant reed, ${ }^{26}$ exhibit good ammonium adsorption performance. Additionally, many studies generally concluded that the BET surface area and pore structure of biochars are the main contributions to the adsorption system..$^{27-29}$ However, the highest ammonium adsorption 
capacity among biochars dose not correlate with the biggest BET surface area, which indicates that biochar properties, such as BET surface area and pore structure have no direct correlation with the ammonium adsorption capacity. ${ }^{13,25,26}$ Therefore, there must be factors influencing biochar ammonium adsorption capacity other than the above properties. In fact, biochar, consists of two main composites, carbon and ash. The former determines the BET surface area and pore structure, whereas the effect of ash has not been studied systematically. Although there are several studies reported on biochars, there are few in-depth studies on the ammonium absorption of biochars derived from biogas residues. Furthermore, although there are some preliminary experiment examining the adsorption mechanism of ion exchange in ash, ${ }^{30,31}$ the specific contribution from $\mathrm{SiO}_{2}$ and minerals in biochar ash are usually neglected, which might be a crucial factor in biochar ammonium adsorption.

Therefore, this study aimed to assess the value of low-cost biochars derived from biogas residues, as efficient alternative absorbents for ammonium removal. Furthermore, the structural properties (composition, porous structure and surface chemistry) and ammonium adsorption of biochars prepared from two typical biogas residues (pig manure biogas residue and straw biogas residue) were compared. More importantly, the effect of ash composition on ammonium adsorption was investigated, providing insight into different the ammonium adsorption mechanism of biochars. This study met the requirements of low-cost and effective ammonium removal, and describes a value-added and environmentally friendly method to treat biogas residue.

\section{Materials and methods}

\subsection{Source of raw materials}

Biogas residues, the raw material for biochars, were by-products of anaerobic digestion from pig manure (PM) and straw (ST) in our own laboratory and were named BR-PM and BR-ST, respectively. All of the chemicals in this study were purchased from Sinopharm Chemical Reagent Co., Ltd. and used as received without further purification.

\subsection{Preparation of biochar}

The biochar precursors BR-PM and BR-ST were chemically activated before being pyrolyzed. One gram of precursors were impregnated in $1 \mathrm{~g} \mathrm{~L}^{-1} \mathrm{KOH}$ solution for $12 \mathrm{~h}$, and dried at $105{ }^{\circ} \mathrm{C}$. Then, the samples were pyrolyzed at $550{ }^{\circ} \mathrm{C}$ for $2 \mathrm{~h}$ with a ramp rate of $5{ }^{\circ} \mathrm{C} \mathrm{min}^{-1}$ in a tube furnace (SK2-1-12, Tianye, China) under a $\mathrm{N}_{2}$ atmosphere $\left(100 \mathrm{~mL} \mathrm{~min}^{-1}\right)$, which was similar to a previous study. ${ }^{32}$ Then, the biochars were washed with excess deionized water and stirred with a glass rod for 5 minutes after pyrolyzation, which was repeated three times. Finally, they were dried at $80^{\circ} \mathrm{C}$ in an oven for $12 \mathrm{~h}$. Accordingly, the two types of biochars were named BC-PM and BC-ST.

\subsection{Analytical methods}

X-ray diffraction (XRD) analysis was performed on an Ultima IV $\mathrm{X}$-ray Diffractometer (Rigaku, Japan) operated at $35 \mathrm{kV}$ and
$10 \mathrm{~mA}$, with a scanning rate of $20^{\circ} \mathrm{min}^{-1}$ and a $2 \theta$ angle ranging from $5^{\circ}$ to $70^{\circ}$ using $\mathrm{CuK} \alpha$ radiation $(\lambda=0.15418 \mathrm{~nm})$. The carbon, nitrogen, hydrogen and sulphur content of the samples were analysed with an elemental analyser (Vario EL III, Elementar, Germany). Ash content was determined by heating the samples at $600{ }^{\circ} \mathrm{C}$ for $4.0 \mathrm{~h}$ with a ramp rate of $10^{\circ} \mathrm{C} \mathrm{min} \mathrm{m}^{-1}$ in a muffle furnace. Fourier transform infrared spectroscopy (FT-IR) spectra were obtained on a Nicolet Avatar 660 (Thermo Electron, USA) using the $\mathrm{KBr}$ pellet method. The cation exchange capacity (CEC) of the biochar was measured using the Schollenberger and Simon method. ${ }^{33}$ The biochar was saturated with $1 \mathrm{~mol} \mathrm{~L}^{-1}$ neutralized ammonium acetate and subsequently washed with $95 \mathrm{v} / \mathrm{v} \%$ alcohol. It was then transferred into a $150 \mathrm{~mL}$ kjeldahl flask to distill and titrate. The BrunauerEmmett-Teller (BET) surface area and average pore size of the biochars were measured using an Automated Physisorption and Chemisorption Analyser (Tristar 3000, USA) with $\mathrm{N}_{2}$ adsorption/ desorption at $-196{ }^{\circ} \mathrm{C}$. All of the samples were degassed at $300{ }^{\circ} \mathrm{C}$ for $2 \mathrm{~h}$ before measurement. Biochar morphology and surface composition were investigated using a scanning electron microscope (SEM) with Energy Dispersion X-ray Spectrometry (EDX) capability (ZEISS SIGMA, Germany).

\subsection{Adsorption of ammonium}

The adsorption performance of the biochars toward ammonium was evaluated using two types of wastewater. One $\mathrm{NH}_{4}{ }^{+}$containing artificial wastewater solution was prepared from $\mathrm{NH}_{4} \mathrm{Cl}$. The concentration of $\mathrm{NH}_{4}{ }^{+}-\mathrm{N}$ was $100 \mathrm{mg} \mathrm{L}{ }^{-1}$, and the initial $\mathrm{pH}$ of the solution was approximately 5.0 without adjustment. A real sample of $\mathrm{NH}_{4}{ }^{+}$-containing wastewater was collected from the supernatant of the biogas slurry produced from pig manure anaerobic digestion in our own laboratory. Its $\mathrm{NH}_{4}{ }^{+}-\mathrm{N}$ concentration was approximately $855 \mathrm{mg} \mathrm{\textrm {L } ^ { - 1 }}$ after centrifugation at approximately $10000 \mathrm{~g}$ (RCF) for $5 \mathrm{~min}$ before use. The detailed quality parameters of the biogas slurry are listed in Table 1.

Kinetics experiments in the two types of wastewater were performed to examine how the adsorption behaviour of ammonium on biochars relate to contact time. Adsorbent $\left(0.03 \mathrm{~g}, 1.0 \mathrm{~g} \mathrm{~L}^{-1}\right)$ was mixed with $30 \mathrm{~mL}$ wastewater solution without adjusting the $\mathrm{pH}$ in a thermostatic shaker at $30{ }^{\circ} \mathrm{C} / 180$ $\mathrm{rpm}$, and the concentration of residual ammonium at different

Table 1 Characteristics of the biogas slurry

\begin{tabular}{lc}
\hline Parameters & $\begin{array}{l}\text { Means and } \\
\text { standard deviati }\end{array}$ \\
\hline $\mathrm{pH}$ & $7.20 \pm 0.20$ \\
$\mathrm{COD}\left(\mathrm{mg} \mathrm{L}^{-1}\right)$ & $980 \pm 12.55$ \\
$\mathrm{NH}_{4}{ }^{+}-\mathrm{N}\left(\mathrm{mg} \mathrm{L}^{-1}\right)$ & $855.73 \pm 12.64$ \\
$\mathrm{PO}_{4}{ }^{3-}-{\mathrm{P}\left(\mathrm{mg} \mathrm{L}^{-1}\right)}_{\mathrm{Ca}\left(\mathrm{m} \mathrm{L} \mathrm{L}^{-1}\right)}^{20.35} \pm 1.84$ \\
$\mathrm{Mg}\left(\mathrm{mg} \mathrm{L}^{-1}\right)$ & $51.90 \pm 0.96$ \\
$\mathrm{~K}\left(\mathrm{mg} \mathrm{L}^{-1}\right)$ & $59.25 \pm 1.22$ \\
$\mathrm{Na}\left(\mathrm{mg} \mathrm{L}^{-1}\right)$ & $240.29 \pm 3.44$ \\
& $121.43 \pm 1.55$
\end{tabular}


time points was measured. The supernatant was filtered through a $0.45 \mu \mathrm{m}$ membrane, and the residual ammonium concentration $\left(C_{t}\right)$ was measured using the Nesslerization method with a Thermo scientific Evolution 220 UV-Visible spectrophotometer at $420 \mathrm{~nm} .^{34}$

The ammonium adsorption capacity of the biochar was calculated according to the mass balance equations

$$
q_{t}=\left(C_{0}-C_{t}\right) V / m
$$

in which $q_{t}$ is the adsorption capacity at time $t(\mathrm{~min}), C_{0}$ is the initial concentration of ammonium $\left(100 \mathrm{mg} \mathrm{L}^{-1}\right), C_{t}$ is the concentration of ammonium at time $t$ of adsorption $\left(\mathrm{mg} \mathrm{L}^{-1}\right), m$ is the mass of adsorbent (g), and $V$ is the volume of solution (L). Adsorption isotherms were obtained during the batch mode adsorption experiments in a thermostatic shaker at $30{ }^{\circ} \mathrm{C} / 180$ rpm. $C_{\mathrm{e}}$ was measured after $0.03 \mathrm{~g}\left(1.0 \mathrm{~g} \mathrm{~L}^{-1}\right)$ biochar was mixed with $30 \mathrm{~mL}$ wastewater for $4.0 \mathrm{~h}$ (reaching complete equilibrium according to our preliminary study). In particular, the $C_{0}$ of the two types of wastewater varied from zero to the initial ammonium concentration by dilution. Then, the equilibrium adsorption capacity $\left(q_{\mathrm{e}}, \mathrm{mg}^{-1}\right)$ was still calculated according to eqn (1). All of the adsorption assays were performed in triplicate.

\section{Results and discussion}

\subsection{Characterization of biogas residues and biochars}

The elemental analysis and ash content of BR-PM, BR-ST, BC-PM and BC-ST, in addition to the BET surface areas, average pore size and biochar yields for both biochars are listed in Table 2. The two types of biogas residue contained similar elemental (CHNS) content. The ash content of BR-PM and BR-ST was $31.21 \pm 1.53 \%$ and $17.75 \pm 0.89 \%$, respectively. However, the derived biochars exhibited a quite different carbon content, ash content and yield. The carbon content of BC-PM was $15.75 \pm 0.14 \%$, whereas that of BC-ST reached 37.59 $\pm 0.16 \%$. The ash content of BC-PM $(62.93 \pm 2.66 \%)$ was higher than that of BC-ST ( $49.67 \pm 2.05 \%)$. More importantly, another distinct difference was the BET surface area, which was higher for BC-ST $\left(260.21 \mathrm{~m}^{2} \mathrm{~g}^{-1}\right)$ than BC-PM $\left(167.88 \mathrm{~m}^{2} \mathrm{~g}^{-1}\right)$. The average pore radius on BC-PM and BC-ST were calculated as 4.08 and $2.57 \mathrm{~nm}$, respectively, using nitrogen adsorption isotherms and classified as mesoporous according to the International Union of Pure and Applied Chemistry (IUPAC). ${ }^{35}$

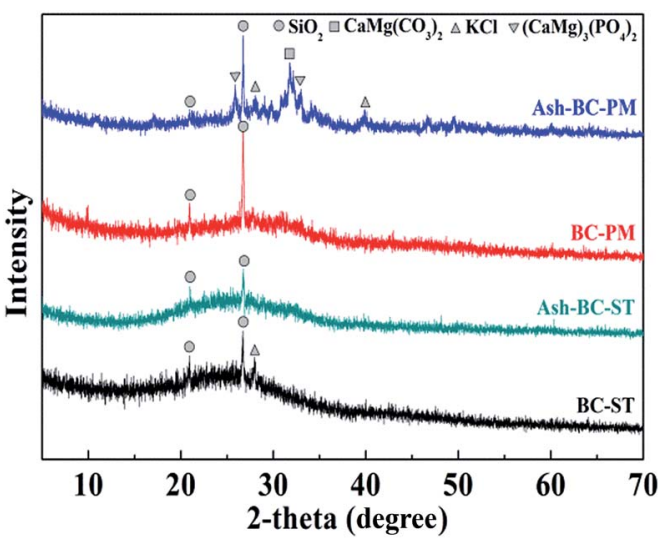

Fig. 1 XRD patterns of BC-PM, BC-ST and their ashes.

The XRD patterns of BC-PM, BC-ST and their ashes are shown in Fig. 1, which was used to probe the short range ordered biochar structures and the presence of miscellaneous crystalline minerals. ${ }^{36}$

There was a sharp peak at $20.99^{\circ}$ and $26.74^{\circ}$ in the two biochars confirming the presence of quartz in both of them. ${ }^{37,38}$ This finding indicated that both of the biochars were amorphous materials, lacking a distinct crystalline structure, and no other significant peaks were observed. However, a few new peaks appeared on Ash-BC-PM, the sample of BC-PM after calcination at $600{ }^{\circ} \mathrm{C}$ in air for $2 \mathrm{~h}$. Specifically, peaks at $26^{\circ}$ and $33^{\circ}$ were assigned to $(\mathrm{CaMg})_{3}\left(\mathrm{PO}_{4}\right)_{2} /$ Whitlockite; peaks at $28^{\circ}$ and $41^{\circ}$ were due to sylvite $(\mathrm{KCl})$, and a peak at $31^{\circ}$ confirmed the presence of $\mathrm{CaMg}\left(\mathrm{CO}_{3}\right)_{2} /$ dolomite. $^{37,39}$ These results suggested that BC-PM actually contained appreciable amounts of metals and carbonate that was absent from the XRD pattern because of the carbon coverage. The minerals might be present within the biochar pores rather than on the biochar surface, therefore, washing the biochars with water is ineffective, and these minerals are evident via XRD only after removing carbon (via calcination). The mineral XRD peaks emerged once the carbon was burnt off. Cao et al. ${ }^{\mathbf{4 0}}$ also similarly reported that biochars derived from dairy manure commonly contained high levels of $\mathrm{Ca}, \mathrm{Mg}$ and P. Furthermore, Herrera et al. ${ }^{41}$ reported that these minerals were from superfluous dietary intakes. As for the Ash-BC-ST XRD pattern, the BC-ST sample after calcination, only one weak peak at $28^{\circ}$ emerged to confirm trace amounts of $\mathrm{KCl}$. Based on the above analysis, $\mathrm{KCl}$ was present in BC-ST as well. Therefore, it can be speculated that BC-ST

Table 2 Composition and characterisation of biogas residues and biochars

Element (means and standard deviations)

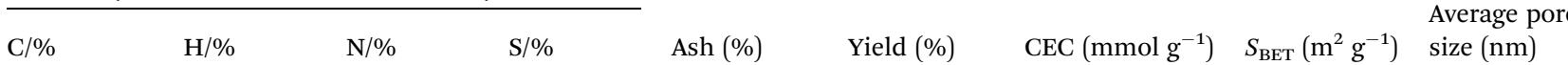

$\begin{array}{llllll}\text { BR-PM } & 33.19 \pm 1.45 & 4.71 \pm 0.42 & 3.75 \pm 0.18 & 0.74 \pm 0.07 & 31.21 \pm 1.53\end{array}$

$\begin{array}{llllll}\text { BR-ST } & 33.06 \pm 0.66 & 4.76 \pm 0.13 & 2.64 \pm 0.07 & 0.40 \pm 0.02 & 17.75 \pm 0.89\end{array}$

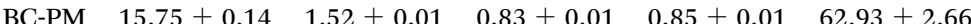

$\begin{array}{llllll}\text { BC-ST } & 37.59 \pm 0.16 & 1.90 \pm 0.03 & 0.80 \pm 0.01 & 0.42 \pm 0.08 & 49.67 \pm 2.05\end{array}$

$48.51 \pm 1.20 \quad 2.18 \pm 0.03 \quad 167.88$

$35.15 \pm 0.45 \quad 0.893 \pm 0.03 \quad 260.21 \quad 2.57$

4.08 

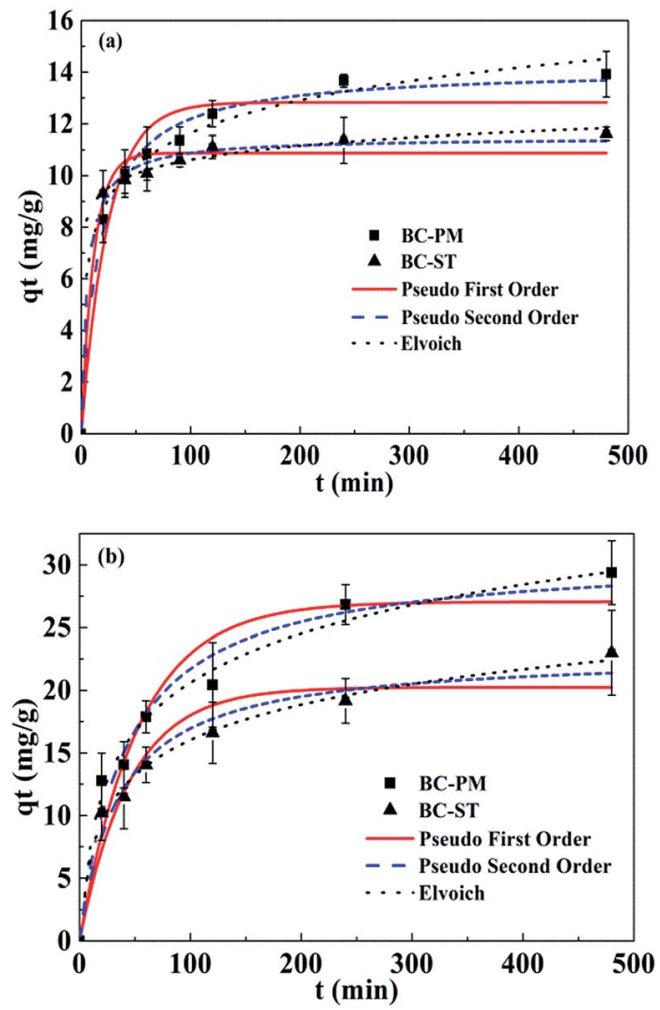

Fig. 2 Kinetics of ammonium adsorption on BC-PM and BC-ST in artificial wastewater (a) and biogas slurry (b) with data fit to pseudofirst-order, pseudo-second-order and Elovich.

contained fewer minerals than BC-PM, which might affect their ammonium adsorption behaviour.

\subsection{Adsorption kinetics study}

The adsorption kinetics on biochars was investigated to determine the time required to reach the adsorption equilibrium and further examine the mechanisms of ammonium adsorption. Fig. 2 shows time dependent ammonium adsorption on BC-PM and BC-ST in artificial wastewater and biogas slurry. In artificial wastewater (Fig. 2a), the ammonium adsorption equilibrium for BC-PM and BC-ST was reached after approximately $4.0 \mathrm{~h}$ with an adsorption capacity of $13.66 \mathrm{mg} \mathrm{g}^{-1}$ and $11.36 \mathrm{mg} \mathrm{g}^{-1}$, respectively, and approximately $80 \%$ and $90 \%$ of the equilibrium adsorption capacity was reached within the first $1.0 \mathrm{~h}$, respectively. In biogas slurry (Fig. 2b), equilibrium was also established in $4.0 \mathrm{~h}$ for BC-PM and BC-ST with an adsorption capacity of $26.82 \mathrm{mg} \mathrm{g}^{-1}$ and $19.16 \mathrm{mg} \mathrm{g}^{-1}$, respectively. The results indicated that ammonium adsorption on the two biochars was a rapid process.

In addition, the kinetics data were also analysed using pseudo-first-order, pseudo-second-order and Elovich models, and the calculated model parameters are shown in Table 3. Elovich models were suitable for describing the ammonium adsorption process in both artificial wastewater and biogas slurry.

\subsection{Adsorption isotherms study}

The adsorption isotherms for ammonium on BC-PM and BC-ST in artificial wastewater (concentration range from 0-100 mg $\mathrm{L}^{-1}$ ) and biogas slurry (concentration range from $0-855 \mathrm{mg} \mathrm{L}^{-1}$ ) fit to the Langmuir and Freundlich models at $30{ }^{\circ} \mathrm{C}$ are presented in Fig. 3. The Langmuir model fit the data better than the Freundlich model for BC-PM, whereas the Freundlich model described the data better for BC-ST. The simulation parameters for the two models are presented in Table 4. In particular, the Langmuir maximum capacity for BC-PM in artificial wastewater and biogas slurry were $37.26 \mathrm{mg} \mathrm{g}^{-1}$ and $48.89 \mathrm{mg} \mathrm{g}^{-1}$, respectively, which were both higher than those of BC-ST for the adsorption of ammonium from artificial wastewater and biogas slurry, respectively.

In general, BC-PM exhibited better ammonium adsorption than BC-ST in artificial wastewater or biogas slurry.

\subsection{Adsorption performance comparison}

To illustrate the potential of the BC-PM and BC-ST prepared in this study as promising biochars for ammonium adsorption with improved ammonium adsorption behaviours, the maximum adsorption capacities of various agro-based biochars in the literatures prepared in similar pyrolyzation conditions were also investigated and compared, as listed in Table 5. The maximum ammonium adsorption capacities of BC-PM and BC-ST reached $37.26 / 48.89 \mathrm{mg} \mathrm{g}^{-1}$ and $21.17 / 28.86 \mathrm{mg} \mathrm{g}^{-1}$ in artificial/real wastewater, respectively, which were much higher

Table 3 Kinetic constants of the various models of ammonium adsorption on BC-PM and BC-ST in artificial wastewater and biogas slurry

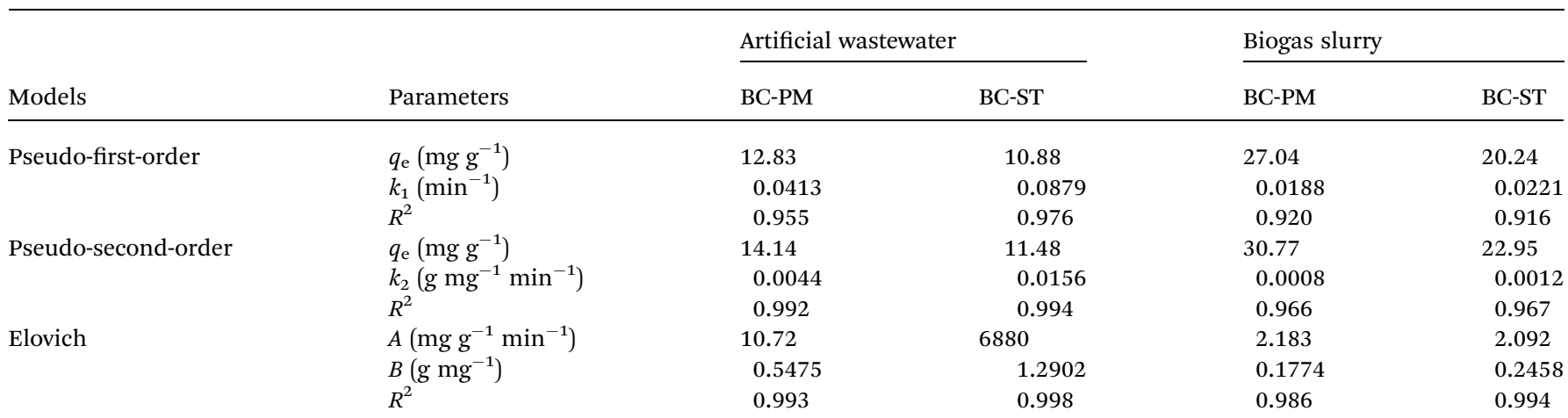



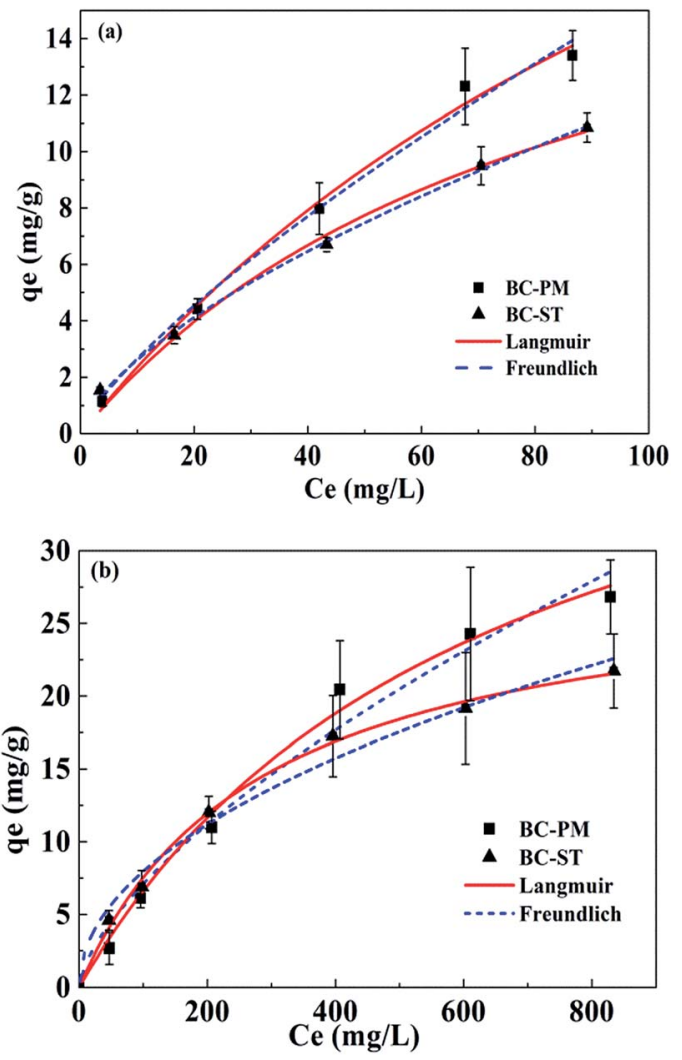

Fig. 3 Isotherms of ammonium adsorption on BC-PM and BC-ST in artificial wastewater (a) and biogas slurry (b) with data fit to the Langmuir and Freundlich models.

Table 4 Langmuir and Freundlich constants for ammonium adsorption on BC-PM and BC-ST in artificial wastewater and biogas slurry

\begin{tabular}{|c|c|c|c|c|c|}
\hline \multirow[b]{2}{*}{ Models } & \multirow[b]{2}{*}{ Parameters } & \multicolumn{2}{|c|}{$\begin{array}{l}\text { Artificial } \\
\text { wastewater }\end{array}$} & \multicolumn{2}{|c|}{ Biogas slurry } \\
\hline & & BC-PM & BC-ST & BC-PM & BC-ST \\
\hline \multirow[t]{3}{*}{ Langmuir } & $q_{\mathrm{m}}\left(\mathrm{mg} \mathrm{g}^{-1}\right)$ & 37.26 & 21.17 & 48.89 & 28.86 \\
\hline & $b\left(\mathrm{~L} \mathrm{mg}^{-1}\right)$ & 0.0068 & 0.0115 & 0.0016 & 0.0035 \\
\hline & $R^{2}$ & 0.992 & 0.985 & 0.993 & 0.997 \\
\hline \multirow[t]{3}{*}{ Freundlich } & $K_{\mathrm{f}}\left(\mathrm{mg} \mathrm{g}^{-1}\right)$ & 0.4553 & 0.5833 & 0.3415 & 0.8268 \\
\hline & $n$ & 1.3039 & 1.5338 & 1.5182 & 2.0340 \\
\hline & $R^{2}$ & 0.988 & 0.998 & 0.976 & 0.983 \\
\hline
\end{tabular}

than biochars prepared from rice husk or hardwood in similar adsorption conditions. It also indicated that biogas residue could be an alternative precursor of the biochars for ammonium adsorption.

\subsection{Ammonium adsorption mechanism}

The above studies showed that BC-PM and BC-ST showed excellent ammonium adsorption performance. As mentioned in the section on BET analysis, BC-PM had a lower specific surface area. However, BC-PM had a higher adsorption capacity than BC-ST, suggesting that the BET surface area is not the main factor in ammonium adsorption. Biochars contain two main components, carbon and ash, and the BET surface area and pore structure were mainly determined by carbon content, leading us to examine the composition and content of the ash in both biochars.

3.5.1 Metal ion exchange in biochars ash. Metal ion exchange is usually seen as an important aspect of ammonium adsorption. ${ }^{25,44}$ In this study, the CEC values of BC-PM and BC-ST were measured as $2.18 \pm 0.3 \mathrm{mmol} \mathrm{g}^{-1}$ and $0.893 \pm 0.3 \mathrm{mmol} \mathrm{g}^{-1}$, respectively (Table 2). Obviously, BC-PM possessed a higher cation exchange capacity than BC-ST indicating that BC-PM might absorb more ammonium through ion exchange than BC-ST. This finding might explain some of the improved BC-PM ammonium adsorption capacity. On the other hand, XRD analysis verified that more metals were present in the BC-PM ash than the BC-ST ash. Thus, the CEC of the two biochars may come from the metals in them. To estimate the contribution of metals and observe the possible transformation of the biochar microscopic structure before and after ammonium adsorption, SEM images and EDX of BC-PM, BC-ST and the corresponding samples after adsorption in artificial wastewater were obtained (Fig. 4a-d). Significant differences in biochar pore structures from BR-PM and BR-ST were clearly observed. Specifically, the surface of BC-PM was rough, whereas BC-ST possessed an apparently porous structure, which corresponded with the BET analysis. There was also no significant change in the pore structures of the biochars after adsorption, indicating they possessed good mechanical properties. However, the element composition varied greatly after adsorption, which was reflected by the SEM-EDX results. The weight percent of metal elements $(\mathrm{Mg}, \mathrm{K}, \mathrm{Ca})$ in BC-PM and BC-ST decreased strongly after adsorption, and $\mathrm{K}$ nearly disappeared, which might be caused by ion exchange with ammonium, an ammonium adsorption mechanism suited to both BC-PM and BC-ST.

3.5.2 $\mathrm{SiO}_{2}$ in biochar ash. The XRD and SEM-EDX results confirmed the effect of metals in biochar ash on ammonium adsorption. However, ammonium adsorption might also be related to the functional groups on the biochar surface. Ammonium adsorption performance of the biochar depends on porosity as well as the active groups on the surface. ${ }^{45}$ Thus, FTIR spectra were collected for qualitative characterization of biochar surface functional groups. The FT-IR results for ammonium adsorption in artificial wastewater after $20 \mathrm{~min}$ and 240 min for BC-PM are shown in Fig. 5a, and those for BC-ST are depicted in Fig. $5 b$.

The broad bands at $3420 \mathrm{~cm}^{-1}$ (Fig. 5a) and $3445 \mathrm{~cm}^{-1}$ (Fig. 5b) were attributed to the $\mathrm{O}-\mathrm{H}$ stretching vibration of BC-PM and BCST, respectively. The bands centred on 1630 (Fig. 5a) and 1618 $\mathrm{cm}^{-1}$ (Fig. $5 \mathrm{~b}$ ) were attributed to $\mathrm{O}-\mathrm{H}$ bending vibrations. ${ }^{46}$ The strong bands for BC-PM and BC-ST at $1025 \mathrm{~cm}^{-1}$ and $1058 \mathrm{~cm}^{-1}$ were assigned to an asymmetric $\mathrm{Si}-\mathrm{O}-\mathrm{Si}$ stretching mode. Peaks at $572 \mathrm{~cm}^{-1}$ and $805 \mathrm{~cm}^{-1}$, neither of which split in two, were assigned to a symmetric $\mathrm{Si}-\mathrm{O}-\mathrm{Si}$ stretching mode. ${ }^{45,47}$ The above results indicated that $\mathrm{SiO}_{2}$ in both biochars was present in an amorphous state, which was also confirmed by the XRD patterns. However, the peaks for asymmetrically stretching $\mathrm{Si}-\mathrm{O}-\mathrm{Si}$ in BC-PM shifted to $1040 \mathrm{~cm}^{-1}$ after $20 \mathrm{~min}$ and $240 \mathrm{~min}$ adsorption. 
Table 5 Comparison of the pyrolyzation conditions and maximum adsorption of ammonium on various agro-based biochars

\begin{tabular}{|c|c|c|c|c|}
\hline Raw materials & Pyrolyzation conditions & Wastewater & $q_{\mathrm{m}}\left(\mathrm{mg} \mathrm{g}^{-1}\right)$ & Ref. \\
\hline Rice husk & $700{ }^{\circ} \mathrm{C}, 2 \mathrm{~h}, 5^{\circ} \mathrm{C} \min$ & Artificial wastewater $\left(\mathrm{NH}_{4} \mathrm{Cl}\right)$ & 3.24 & 30 \\
\hline Hardwood shavings & $300{ }^{\circ} \mathrm{C}, 8-10 \mathrm{~h}, \mathrm{~nm}^{a}$ & Dairy manure effluent & 5.3 & 42 \\
\hline Thalia dealbata & $600{ }^{\circ} \mathrm{C}, 2 \mathrm{~h}, 5^{\circ} \mathrm{C} \min$ & Artificial wastewater $\left(\mathrm{NH}_{4} \mathrm{Cl}\right)$ & 11.2 & 25 \\
\hline Giant reed (Arundo donaxL.) & $300{ }^{\circ} \mathrm{C}, 2 \mathrm{~h}, 10^{\circ} \mathrm{C} \min$ & Artificial wastewater $\left(\mathrm{NH}_{4} \mathrm{Cl}\right)$ & 2.10 & 26 \\
\hline Lignite & $300^{\circ} \mathrm{C}, 18 \mathrm{~h}, \mathrm{~nm}^{a}$ & Artificial wastewater $\left(\mathrm{NH}_{4} \mathrm{Cl}\right)$ & 28.43 & 43 \\
\hline
\end{tabular}

${ }^{a}$ Ramp rate is not mentioned.
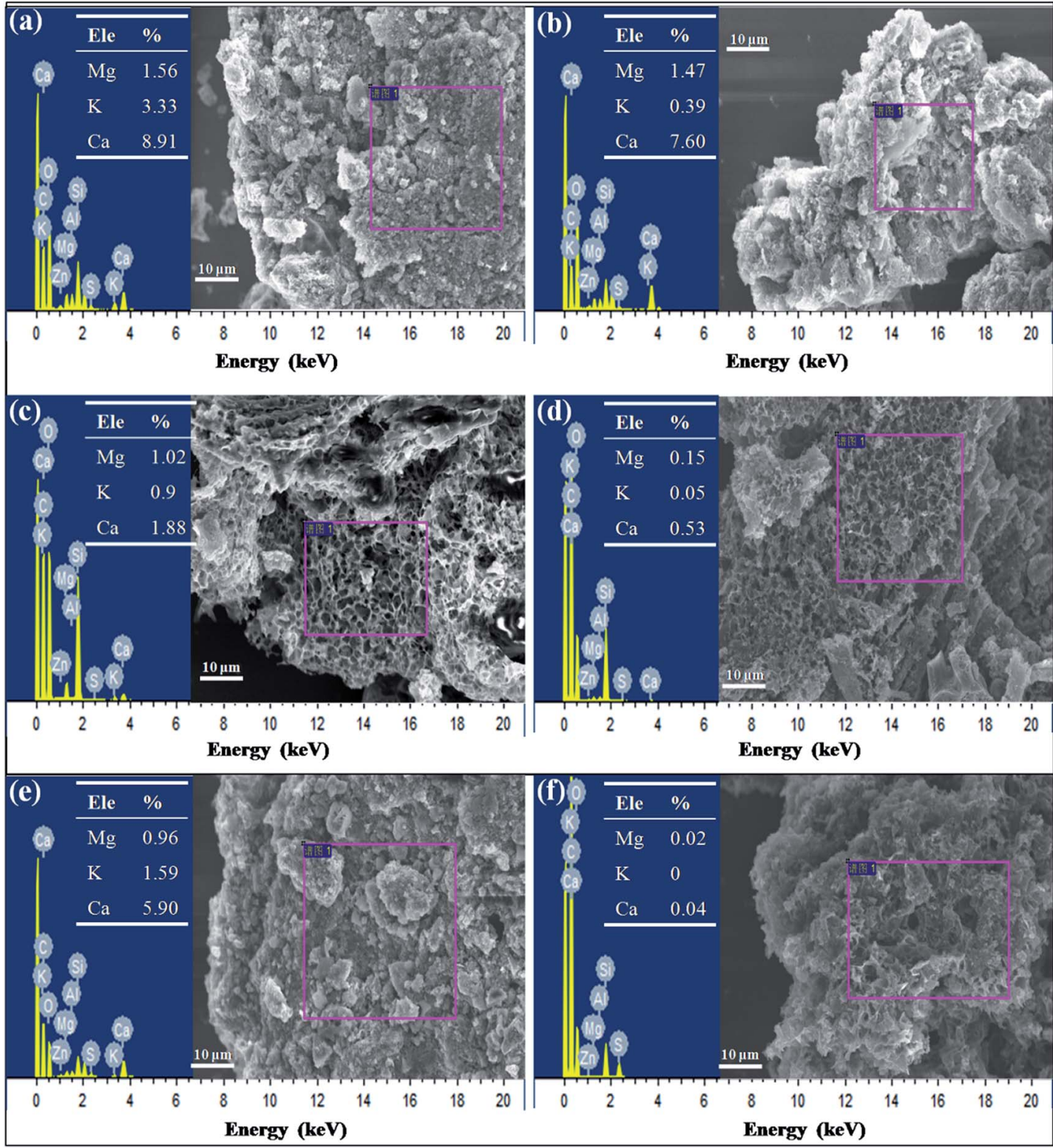

Fig. 4 SEM images and EDX spectra analyses of BC-PM (a), BC-ST (c), the same samples after the adsorption of ammonium (b, d), and BC-PM treated with water (e) and $\mathrm{HCl}(f)$. 

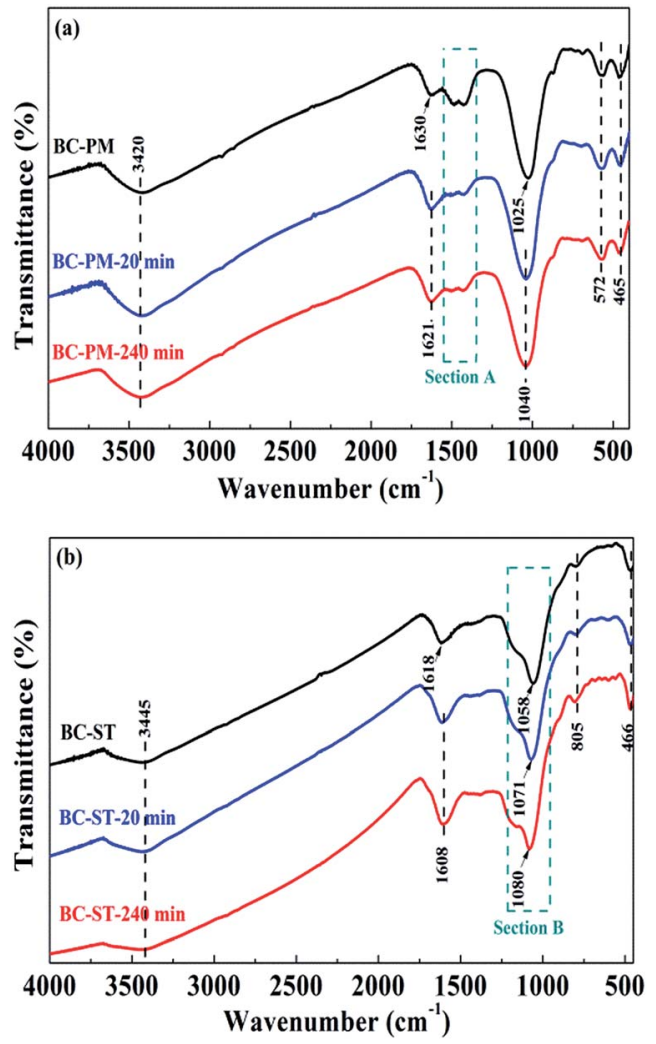

Fig. 5 FT-IR spectra of BC-PM (a), BC-ST (b) and the same samples after ammonium adsorption at $20 \mathrm{~min}$ and $240 \mathrm{~min}$.

In addition, the peaks for asymmetrically stretching $\mathrm{Si}-\mathrm{O}-\mathrm{Si}$ were also detected to show a blue-shift after adsorption by BC-ST. Specifically, as shown in section B (Fig. 5b), $13 \mathrm{~cm}^{-1}$ was shifted in the first $20 \mathrm{~min}$, and another $9 \mathrm{~cm}^{-1}$ in the later $220 \mathrm{~min}$. These shifts can be attributed to electrostatic interactions between $\mathrm{SiO}_{2}$ and ammonium, and the $\mathrm{SiO}_{2}$ in the biochars may have acted as ammonium adsorption sites, playing a significant role in the process. $\mathrm{Si}-\mathrm{O}-\mathrm{Si}$, the main functional groups on the two biochars, was from $\mathrm{SiO}_{2}$ in biochar ash. Thus, another component in biochar ash was verified to contribute to ammonium adsorption.

3.5.3 Carbonate minerals in the ash of biochars. Compared with the FT-IR spectrum of BC-ST, that of BC-PM showed a distinctive region weakened after adsorption (section $\mathrm{A}$ in Fig. 5a). The peaks at 1484 and $1426 \mathrm{~cm}^{-1}$ were assigned to $\mathrm{CO}_{3}{ }^{2-}$ of the mineral components (carbonates) in biochars originating from pyrolyzation, ${ }^{\mathbf{4 0 , 4 8}}$ and they also belonged to BC-PM ash according to the XRD analysis. In addition, the EDX results shown in Fig. 4 suggest that the BC-PM metal content was much higher than BC-ST. The carbonates might serve as additional ammonium adsorption sites, contributing to BC-PM's high adsorption capacity.

To verify their exact effect on ammonium adsorption, BC-PM was treated with water for $8 \mathrm{~h}$ because carbonates dissolve in water after a long treatment time. As expected, water treatment weakened the FT-IR peaks for carbonates, which is shown in section C of Fig. 6a. Furthermore, the ash content of water
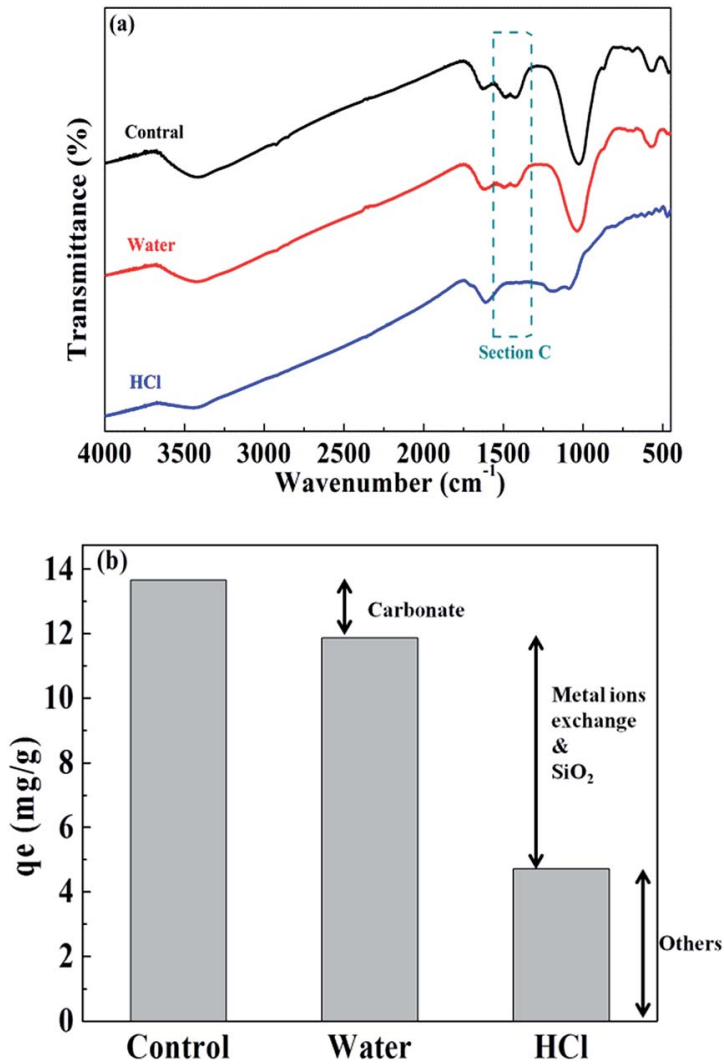

Fig. 6 Comparison of the FT-IR spectra of BC-PM after various treatments (a) and the ammonium adsorption capacity contribution of different components (b).

treated with BC-PM barely decreased, and the EDX spectra analyses of BC-PM treated by water (Fig. 4e) also showed that its metal content was barely decreased. Accordingly, BC-PM's ammonium adsorption capacity only decreased to $11.87 \mathrm{mg} \mathrm{g}^{-1}$ from $13.66 \mathrm{mg} \mathrm{g}^{-1}$ of the control as shown in Fig. $6 \mathrm{~b}$. Thus, the reduced ammonium adsorption capacity $\left(1.79 \mathrm{mg} \mathrm{g}^{-1}\right)$ on water treated BC-PM might be attributed to the slight dissolution of carbonate and the accompanying decreasing additional ammonium adsorption sites on mineral components.

For HCl-treated BC-PM, the ash content fell sharply to $35.27 \%$ from $62.93 \%$. The SEM imaging and EDX spectral analyses (Fig. 4f) showed that the structure became more porous, and the metal content $(\mathrm{Mg}, \mathrm{K}, \mathrm{Ca})$ was nearly zero, owing to the dissolution of mineral components by $\mathrm{HCl}$. The results of FT-IR (Fig. 6a) showed that the carbonates peaks disappeared and $\mathrm{SiO}_{2}$ peaks weakened after $\mathrm{HCl}$ treatment. Accordingly, the ammonium adsorption capacity decreased from $13.66 \mathrm{mg} \mathrm{g}^{-1}$ to $4.72 \mathrm{mg} \mathrm{g}^{-1}$. Thus, the reduced ammonium adsorption capacity $\left(8.94 \mathrm{mg} \mathrm{g}^{-1}\right.$ ) on HCl-treated BC-PM was not caused by the same phenomenon as water treatment, but rather by a combined action of missing metal ion exchange, carbonates and reduced $\mathrm{SiO}_{2}$. In addition, the porous structure of biochar enhanced by $\mathrm{HCl}$ treatment seemed to have little effect promoting ammonium adsorption capacity. In general, the effect of carbonate mineral components on additional 
adsorption sites in biochar for ammonium adsorption was less than metal ion exchange and $\mathrm{SiO}_{2}$ effect.

\section{Conclusions}

Two biochars (BC-PM and BC-ST) were prepared from pig manure and straw biogas residues through activation and then pyrolyzation. They both exhibited good ammonium adsorption in artificial wastewater and biogas slurry. The kinetics of ammonium adsorption on BC-PM and BC-ST both follow the Elovich model. Adsorption isotherm analysis indicated that BC-PM and BC-ST both fit the Langmuir model well, although BC-ST possessed a lower adsorption capacity than BC-PM. The BET surface area and biochar pore structure had no direct correlation with ammonium adsorption capacities. However, the ash in the biochars played an important role in ammonium adsorption. The metal elements in the biochars ash decreased as a result of ion exchange with ammonium. $\mathrm{SiO}_{2}$ and carbonate mineral components in biochar ash also function as ammonium adsorption sites.

\section{Acknowledgements}

This work was supported by the National Basic Research Program of China (2013CB733505), the National Natural Science Foundation of China (41276101), the Zhejiang Provincial Key Research Project (2014C03022) and the Science and Technology Program of Xiamen, China (3502Z20143008).

\section{References}

1 S. Chen, B. Chen and D. Song, Bioresour. Technol., 2012, 114, 357-364.

2 J. Moller, A. Boldrin and T. H. Christensen, Waste Manage. Res., 2009, 27, 813-824.

3 J. Abubaker, K. Risberg and M. Pell, Appl. Energy, 2012, 99, 126-134.

4 V. Arthurson, Energies, 2009, 2, 226-242.

5 C. E. Marcato, E. Pinelli, P. Pouech, P. Winterton and M. Guiresse, Bioresour. Technol., 2008, 99, 2340-2348.

6 S. Zhang and Y. Xiong, RSC Adv., 2016, 6, 5270-5277.

7 C. Gan, Y. Liu, X. Tan, S. Wang, G. Zeng, B. Zheng, T. Li,

Z. Jiang and W. Liu, RSC Adv., 2015, 5, 35107-35115.

8 T. Xie, K. R. Reddy, C. Wang, E. Yargicoglu and K. Spokas, Crit. Rev. Environ. Sci. Technol., 2015, 45, 939-969.

9 H. Lu, W. Zhang, Y. Yang, X. Huang, S. Wang and R. Qiu, Water Res., 2012, 46, 854-862.

10 B. Chen, D. Zhou and L. Zhu, Environ. Sci. Technol., 2008, 42, 5137-5143.

11 X. Xu, X. Cao, L. Zhao, H. Zhou and Q. Luo, RSC Adv., 2014, 4, 44930-44937.

12 D. Angin, T. E. Köse and U. Selengil, Appl. Surf. Sci., 2013, 280, 705-710.

13 Y. Zhang, Z. Li and I. B. Mahmood, Front. Environ. Sci. Eng., 2014, 8, 825-834.

14 S. H. Lin and C. L. Wu, Water Res., 1996, 30, 1851-1857.
15 M. A. Wahab, H. Boubakri, S. Jellali and N. Jedidi, J. Hazard. Mater., 2012, 241-242, 101-109.

16 A. Haralambous, E. Maliou and M. Malamis, Water Sci. Technol., 1992, 25, 139-145.

17 M. Sarioglu, Sep. Purif. Technol., 2005, 41, 1-11.

18 A. Thornton, P. Pearce and S. A. Parsons, Water Res., 2007, 41, 433-439.

19 M. Uğurlu and M. H. Karaoğlu, Microporous Mesoporous Mater., 2011, 139, 173-178.

20 S. Balci, Water Res., 2004, 38, 1129-1138.

21 Y. Yao, B. Gao, M. Inyang, A. R. Zimmerman, X. Cao, P. Pullammanappallil and L. Yang, J. Hazard. Mater., 2011, 190, 501-507.

22 E. R. Orskov, K. Yongabi Anchang, M. Subedi and J. Smith, Biomass Bioenergy, 2014, 70, 4-16.

23 J. Maroušek, Clean Technol. Environ. Policy, 2014, 16, 18211825.

24 Y. Yao, B. Gao, M. Inyang, A. R. Zimmerman, X. Cao, P. Pullammanappallil and L. Yang, Bioresour. Technol., 2011, 102, 6273-6278.

25 Z. Zeng, S. D. Zhang, T. Q. Li, F. L. Zhao, Z. L. He, H. P. Zhao, X. E. Yang, H. L. Wang, J. Zhao and M. T. Rafiq, J. Zhejiang Univ., Sci., B, 2013, 14, 1152-1161.

26 H. Zheng, Z. Wang, X. Deng, J. Zhao, Y. Luo, J. Novak, S. Herbert and B. Xing, Bioresour. Technol., 2013, 130, 463471.

27 A. Zielińska and P. Oleszczuk, Bioresour. Technol., 2015, 192, 618-626.

28 L. Xiao, E. Bi, B. Du, X. Zhao and C. Xing, Environ. Earth Sci., 2014, 71, 5195-5205.

29 C. Jung, J. Park, K. Lim, S. Park, J. Heo, N. Her, J. Oh, S. Yun and Y. Yoon, J. Hazard. Mater., 2013, 263, 702-710.

30 K. Zhu, H. Fu, J. Zhang, X. Lv, J. Tang and X. Xu, Biomass Bioenergy, 2012, 43, 18-25.

31 S. E. Hale, V. Alling, V. Martinsen, J. Mulder, G. D. Breedveld and G. Cornelissen, Chemosphere, 2013, 91, 1612-1619.

32 G. H. Oh and C. R. Park, Fuel, 2002, 81, 327-336.

33 C. Schollenberger and R. Simon, Soil Sci., 1945, 59, 13-24.

34 A. M. Yusof, L. K. Keat, Z. Ibrahim, Z. A. Majid and N. A. Nizam, J. Hazard. Mater., 2010, 174, 380-385.

35 K. Sing, D. Everett, R. Haul, L. Moscou, R. Pierotti, J. Rouquerol and T. Siemieniewska, Pure Appl. Chem., 1985, 57, 603-619.

36 C. Liao, C. Wu and Y. Yan, Fuel Process. Technol., 2007, 88, 149-156.

37 R. Azargohar, S. Nanda, J. A. Kozinski, A. K. Dalai and R. Sutarto, Fuel, 2014, 125, 90-100.

38 N. V. Farinella, G. D. Matos and M. A. Z. Arruda, Bioresour. Technol., 2007, 98, 1940-1946.

39 C. Chen, W. Zhou and D. Lin, Bioresour. Technol., 2014, 179, 359-366.

40 X. Cao and W. Harris, Bioresour. Technol., 2010, 101, 52225228.

41 D. Herrera, W. Harris, V. Nair, M. Josan and C. Staples, J. Dairy Sci., 2010, 93, 2598-2611.

42 D. V. Sarkhot, T. A. Ghezzehei and A. A. Berhe, J. Environ. Qual., 2013, 42, 1545-1554. 
43 P. Vassileva, P. Tzvetkova and R. Nickolov, Fuel, 2009, 88, 46 M. Wang, L. Liao, X. Zhang, Z. Li, Z. Xia and W. Cao, Clays 387-390. Clay Miner., 2011, 59, 459-465.

44 H. Huang, X. Xiao, B. Yan and L. Yang, J. Hazard. Mater., 47 A. M. Yusof, N. A. Nizam and N. A. A. Rashid, J. Porous Mater., 2010, 175, 247-252. 2009, 17, 39-47.

45 V. Sricharoenchaikul, C. Pechyen, D. Aht-ong and D. Atong, 48 X. Xu, X. Cao, L. Zhao, H. Wang, H. Yu and B. Gao, Environ. Energy Fuels, 2007, 22, 31-37. Sci. Pollut. Res., 2013, 20, 358-368. 